\title{
Analysis of Characteristics and Feasibility of High-pressure- and Low-temperature Water Jet Method of Exploiting Marine Natural Gas Hydrate
}

\section{T. Li, C. Chen, L. Yang, Y. Chen, D. B. Pan, X. P. Zhong, and Y. Zhang}

Key Laboratory of Drilling and Exploitation Technology in Complex Conditions of Ministry of Land and Resources, College of Construction Engineering, Jilin University, Changchun, China

\section{Abstract}

Marine natural gas hydrate (MNGH) accounts for $99 \%$ of the global hydrate resources, $90 \%$ of which are deposited in marine clayey silt sediments. MNGH has great economic benefits; however, the large-scale commercial exploitation of hydrates is severely restricted by technology. High-pressure- and low-temperature water jet

Corresponding Author:

C. Chen

chenchen@jlu.edu.cn

Received: 14 September 2018

Accepted: 1 October 2018

Published: 14 October 2018

Publishing services provided by Knowledge

(c) X. T. Li et al. This article is distributed under the terms of the Creative Commons

Attribution License, which permits unrestricted use and redistribution provided that the original author and source are credited.

Selection and Peer-review under the responsibility of the ASRTU Conference Committee.

\section{G OPEN ACCESS} method is a new kind of MNGH solid exploitation method. This article represents analysis of its characteristics and determination of the critical velocity by laboratory experiment. Results show that the new method is feasible for MNGH exploitation, and the present study can provide reference for subsequent MNGH exploitation research and engineering applications.

Keywords: marine natural gas hydrate, solid exploitation method, high-pressure water jet, critical velocity

\section{Introduction}

Natural gas hydrate (NGH) has always been considered an important potential energy source. It has a wide distribution range, large resource reserves, and high energy density, each volume of hydrate is typically equivalent to $160-180$ volumes of methane gas $[1,2]$. With the increasing importance of natural gas in today's energy structure, possibility of exploitation of natural gas hydrates has become an international research hotspot $[3,4]$. Marine natural gas hydrate (MNGH) accounts for $99 \%$ of the global hydrate resources, $90 \%$ of which are deposited in marine clayey silt sediments [5]. Because of its enormous reserves, hydrate in clayey silt sediments has great economic benefits and development prospects [6]. However, the large-scale commercial exploitation of hydrates is severely restricted by technology [7, 8]. In order to expand 
the hydrate technology reserves, it is very important to develop MNGH exploitation technology $[9,10]$.

At present, the research on the exploitation technology of NGH and the development of related production systems are still in the early stage [11]. Conventional NGH exploitation methods mainly include depressurization, thermal stimulation, inhibitor injection, $\mathrm{CO}_{2}$ replacement method, combined exploitation method, and solid exploitation method [12, 13]. International NGH field production is shown in Table 1 [14]. The first three ones use NGH instability dissociation characteristics to extract natural gas, while the more recent $\mathrm{CO}_{2}$ replacement method, combined exploitation method, and solid exploitation method have unique production mechanism, corresponding to the suitable hydrate-bearing area $[15,16]$. In terms of research level, depressurization has been extensively studied and widely recognized in many countries, and field production tests have been carried out in many places [17]. Thermal stimulation and inhibitor injection are no longer used alone because of the low efficiency. Other methods are still in their infancy and further research is needed $[18,19]$.

Although many methods have been carried out in the field production tests, the gap between theoretical research and practical engineering applications is still large [20]. And current methods for MNGH exploitation are mainly used for hydrate in sand sediments, which have certain limitations and cannot meet commercial production requirements $[21,22]$. Therefore, there are still many production mechanisms and process technical problems that need to be solved, and there is an urgent need for safe, efficient, and economical MNGH exploitation methods.

According to the characteristics of MNGH reservoirs, which meet the requirements of high pressure water jet technology [23, 24], we propose high pressure and low temperature water jet method for MNGH exploitation. In this article, we have assessed the progress in current MNGH exploitation method research, MNGH trials exploitation project, and project termination reason. Based on it, we have analyzed the research status and characteristics of the solid exploitation method, which is recognized as a promising new method. The high pressure and low temperature water jet method is compared with the current methods to study its characteristics and analyze its advantages and differences with other solid exploitation technologies. A self-developed multi-functional rock crushed simulation test device has been used for high pressure and low temperature water jet method test; we have analyzed its characteristics, determined the critical velocity, and also analyzed its feasibility and prospect. 
TABLE 1: International NGH field production.

\begin{tabular}{|c|c|c|c|c|c|c|}
\hline Time & Location & Reservoir & Method & $\begin{array}{l}\text { Production } \\
\text { Time (days) }\end{array}$ & $\begin{array}{l}\text { Total gas } \\
\text { production } \\
\text { (m3) }\end{array}$ & $\begin{array}{l}\text { Termination } \\
\text { reason }\end{array}$ \\
\hline 1967 & $\begin{array}{l}\text { Messoyakha, } \\
\text { Russia }\end{array}$ & $\begin{array}{c}\text { Sand } \\
\text { sediments }\end{array}$ & Inhibitor injection & - & - & $\begin{array}{c}\text { Completed, } \\
\text { Low } \\
\text { production } \\
\text { efficiency }\end{array}$ \\
\hline 2002 & $\begin{array}{l}\text { Mackenzie } \\
\text { Delta, Canada }\end{array}$ & $\begin{array}{c}\text { Sand } \\
\text { sediments }\end{array}$ & $\begin{array}{l}\text { Thermal } \\
\text { stimulation }\end{array}$ & 5 & 463 & $\begin{array}{l}\text { Low } \\
\text { production } \\
\text { efficiency \& } \\
\text { Sand } \\
\text { production }\end{array}$ \\
\hline 2007 & & & Depressurization & 0.5 & 830 & \\
\hline 2008 & & & Depressurization & 6 & 13000 & \\
\hline 2012 & Alaska, USA & $\begin{array}{c}\text { Sand } \\
\text { sediments }\end{array}$ & $\mathrm{CO}_{2}$ replacement & 30 & 24000 & $\begin{array}{l}\text { Low } \\
\text { production } \\
\text { efficiency }\end{array}$ \\
\hline 2013 & $\begin{array}{c}\text { Eastern } \\
\text { Nankai } \\
\text { trough, Japan }\end{array}$ & $\begin{array}{c}\text { Sand } \\
\text { sediments }\end{array}$ & Depressurization & 6 & 119000 & $\begin{array}{c}\text { Severe sand } \\
\text { production }\end{array}$ \\
\hline 2017.5 & & $\begin{array}{c}\text { Sand } \\
\text { sediments }\end{array}$ & Depressurization & 12 & 35000 & $\begin{array}{l}\text { Severe sand } \\
\text { production }\end{array}$ \\
\hline 2017.6 & & $\begin{array}{c}\text { Sand } \\
\text { sediments }\end{array}$ & Depressurization & 24 & 200000 & $\begin{array}{c}\text { Completed, } \\
\text { low } \\
\text { production } \\
\text { efficiency }\end{array}$ \\
\hline 2017.5 & $\begin{array}{l}\text { South Sea, } \\
\text { China }\end{array}$ & $\begin{array}{l}\text { Clayey silt } \\
\text { sediments }\end{array}$ & $\begin{array}{c}\text { Improved } \\
\text { depressurization }\end{array}$ & 60 & 309000 & $\begin{array}{c}\text { Completed, } \\
\text { low } \\
\text { production } \\
\text { efficiency }\end{array}$ \\
\hline 2017.5 & $\begin{array}{l}\text { South Sea, } \\
\text { China }\end{array}$ & $\begin{array}{l}\text { Clayey silt } \\
\text { sediments }\end{array}$ & $\begin{array}{l}\text { Solid exploitation } \\
\text { method }\end{array}$ & - & - & $\begin{array}{c}\text { Completed, } \\
\text { low } \\
\text { production } \\
\text { efficiency }\end{array}$ \\
\hline
\end{tabular}

\section{Methods}

According to the low temperature, high pressure, shallow buried depth, and low consolidation characteristics of MNGH bearing sediments, which meet the requirements of high pressure water jet technology [22, 23], we propose high pressure and low temperature water jet method of exploiting MNGH. The MNGH bearing sediments are cut and broken in the submerged environment by regulating the velocity, pressure, and temperature parameters of water jet. The hydrate particles are transported by hydraulic pipeline, and the safety dissociation of hydrates is controlled during the mining process, so that the natural gas can be obtained. 
The high pressure and low temperature water jet method belongs to solid exploitation methods. Compared with other current MNGH exploitation methods, it has the advantages of solid exploitation methods [24]. Because the high pressure water jet is used as the working medium, the method has the advantages of deeper exploitation depth and smaller operation surface. Moreover, the broken particles are more uniform, so there is also no need for the complicated grinding process on the seabed [25]. At the same time, the friction loss of the mechanical rotary drilling tool is avoided [26].

We use a self-developed multi-functional rock crushed simulation test device for studying high pressure water jet breaking of hydrate sediments. The test sample of hydrate bearing sediments was synthesized using tetrahydrofuran (THF) and sea sand, and the breaking test of THF bearing hydrate sediments under the high pressure water jet was carried out to analyze characteristics and feasibility of high pressure and low temperature water jet method.

This self-developed multi-functional rock crushed simulation test device is shown in Figures 1 and 2. Technical indices of the test device are as follows. The maximum pressure of the visible chamber reactor is $15 \mathrm{MPa}$, the size of the sample is $60 \times 60$ $x 150 \mathrm{~mm}^{3}$, the maximum pressure of the constant speed and pressure pump is 25 $\mathrm{MPa}$, the maximum working pressure of the high pressure water jet pump is $20 \mathrm{MPa}$, the flow rate is $0 \sim 2.5 \mathrm{~L} / \mathrm{min}$, the inner diameter of the water jet nozzle is $1 \mathrm{~mm}$, the precision error of the pressure sensor is superior to $0.2 \% \mathrm{~F} . \mathrm{S}$, the working temperature of the constant temperature box is $-20 \sim 50^{\circ} \mathrm{C}$.

The experiment used THF solution of $99.9 \%$ purity, sea sand was washed and dried by distilled water. The median diameter of sea sand was $1 \mathrm{~mm}$ after sieving. Saturation of the sample is $50 \%$. According to the equations (1-4), the amount of the solution was calculated.

$$
\begin{gathered}
V_{\varphi s 2}=V_{s 1} *\left(K+\varphi_{a}-1\right) \\
V_{l}=V_{\varphi_{s 2}} * S_{H} \\
V_{T H F}+V_{w}=V_{l} \\
\frac{\rho_{T H F} V_{T H F}}{\rho_{T H F} V_{T H F}+\rho_{w} V_{w}}=19 \%,
\end{gathered}
$$

where $V_{s 1}$ - volume of chamber, $\mathrm{K}$ - degree of compaction of sea sand, $\varphi_{a}$ - accumulation porosity of the sea sand, $V_{\varphi s 2}$ - pore volume of the sample, $V_{l}$ - liquid volume, $S_{H}$ - saturation of the sample, $V_{T H F}$ - volume of THF, $V_{w}$ - volume of water. 


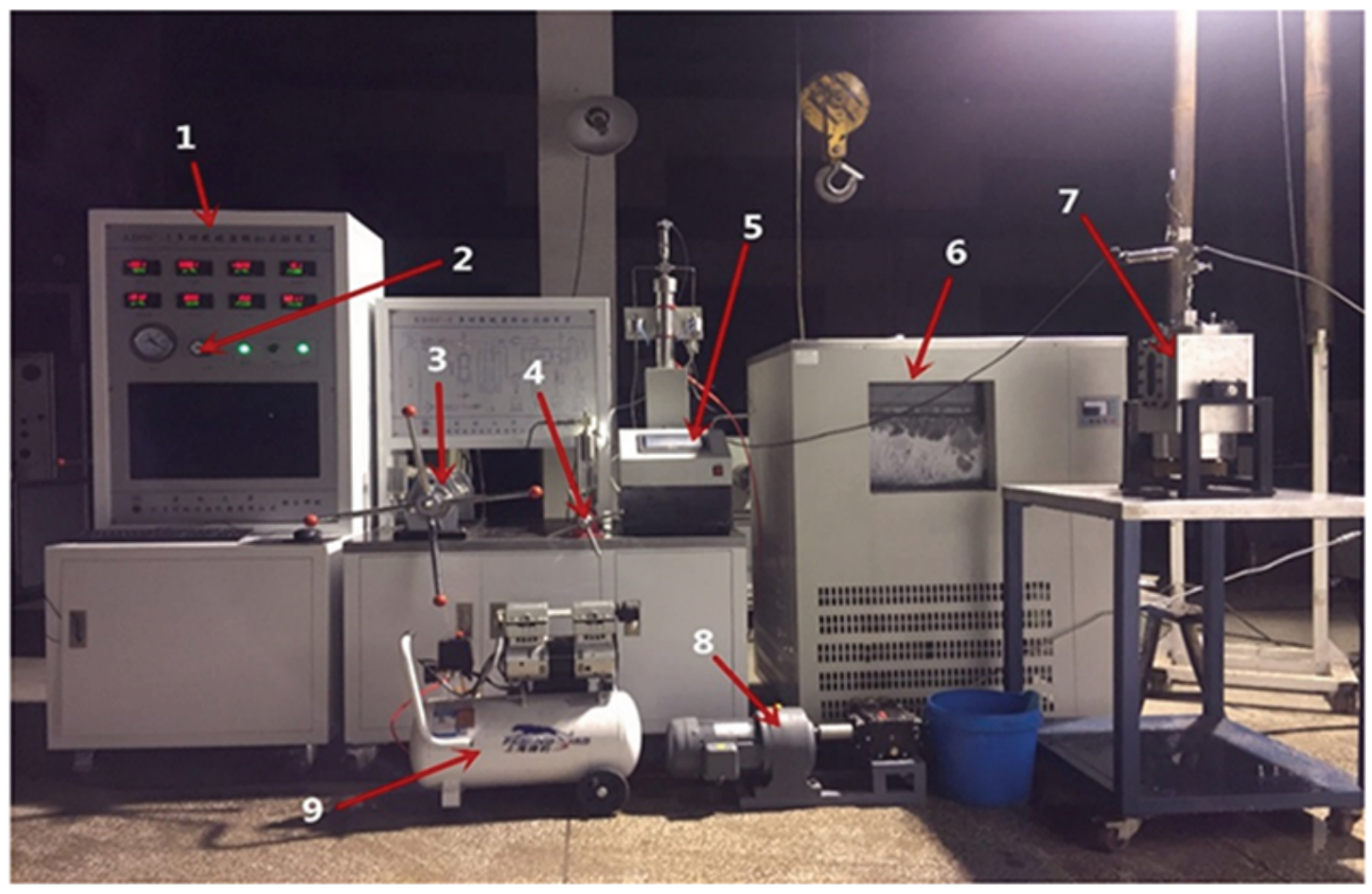

Figure 1: Multi-functional rock crushed simulation test device: 1 - control cabinet; 2 - pressure regulating valve; 3 -confining pressure hand pump; 4 - gas injection hand pump; 5 -constant speed and pressure axial pressure pump; 6 - incubator; 7 - visible chamber reactor; 8 - water jet pump; 9 - vacuum pump.

After calculation, the volume of sea sand was $866.44 \mathrm{~cm}^{3}$, THF was $24.78 \mathrm{ml}$, and distilled water was $88.07 \mathrm{ml}$; the THF solution was configured for standby. The experimental operation included the following operations:

1. mix the prepared THF solution with sea sand evenly, put it into the test chamber, install the upper cover of the test chamber, and seal it;

2. connect the pipeline, set constant speed and pressure axial pressure pump to 3 $\mathrm{MPa}$, set confining pressure to $1 \mathrm{MPa}$, and compact the sample;

3. after the compaction, check the tightness of the pipe and the thread interface, put the reactor into the constant temperature water bath to synthesize hydrates. The temperature of the water bath was set to $-9^{\circ} \mathrm{C}$ and the synthesis time was 24 h;

4. after the hydrate was completely synthesized, connect the water jet nozzle and drainage pipeline. Set water jet flow velocity to $1100 \mathrm{ml} / \mathrm{min}$ (experiment 1), 1300 $\mathrm{ml} / \mathrm{min}$ (experiment 2), $1500 \mathrm{ml} / \mathrm{min}$ (experiment 3), and $1700 \mathrm{ml} / \mathrm{min}$ (experiment 4) separately, set the jet distance to $0.5 \mathrm{~cm}$. Then open the high pressure water pump to break the hydrate sediment, and keep the water jet during $30 \mathrm{~s}$; 


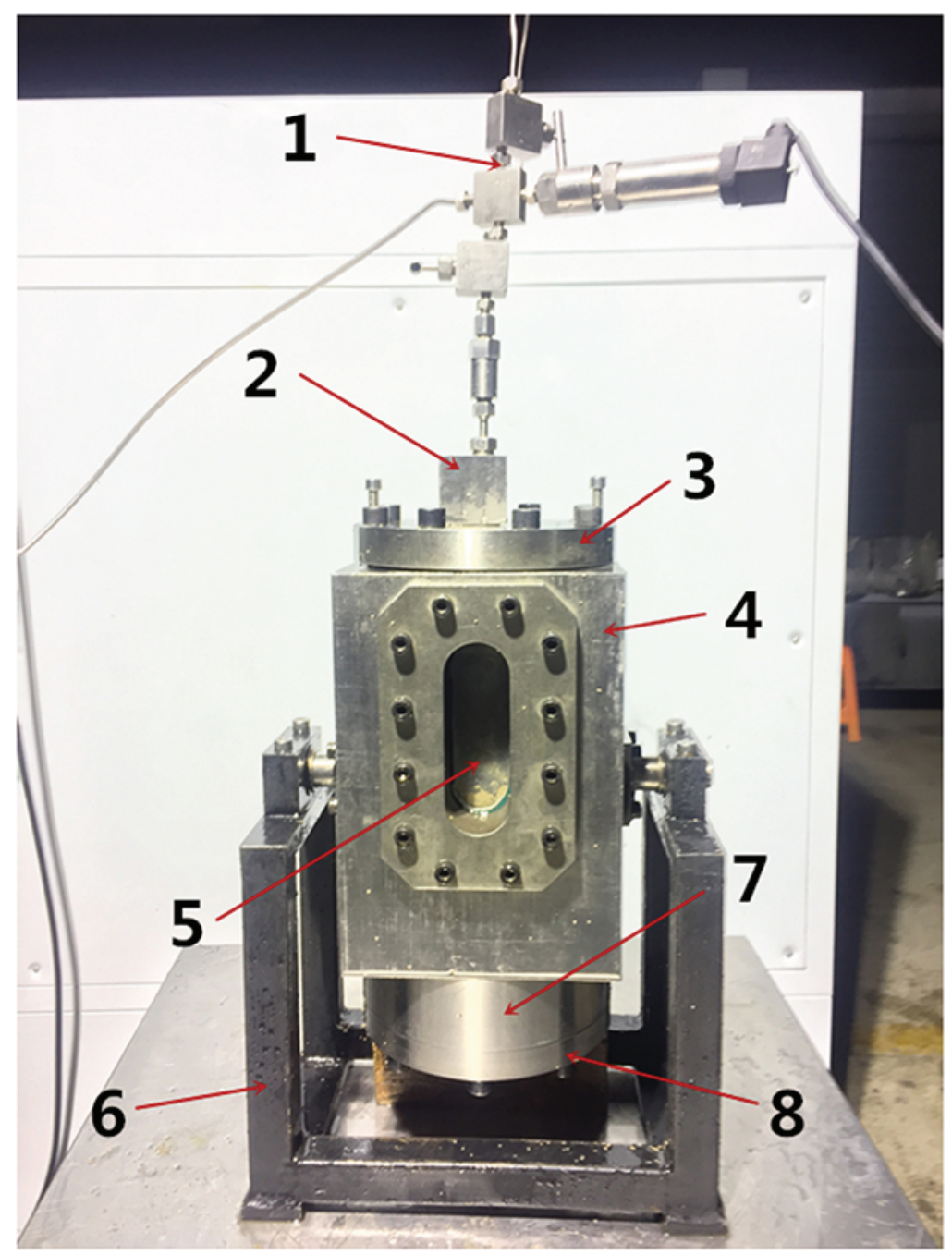

Figure 2: Front view of visible chamber reactor: 1 - nozzle; 2 - tee coupling; 3 - upper cover; 4 - visible chamber; 5 - sapphire window; 6 - support; 7 - axial pressure loading chamber; 8 - bottom cover.

5. after the experiment, open the upper cover and eliminate the residual liquid and the broken sand. Then start observing the breaking effect, measure the brokenrock volume, the breaking depth, and the diameter of the breaking pit.

\section{Results}

The 3D dimension of pit was measured after the water jet breaking experiment, the result is shown in Table 2 . With experiment 1 (flow velocity $1100 \mathrm{ml} / \mathrm{min}$ ) as the basic group, the broken-rock volume and depth of the pit increased with the increase of the water jet flow velocity. The broken-rock volume increased by $28.40 \%, 31.73 \%$, and $36.50 \%$, respectively, while the breaking depth increased by $7.85 \%, 3.99 \%$, and $1.81 \%$, respectively. 
TABLE 2: Experimental results of hydrate deposits under different jet flow conditions.

\begin{tabular}{|c|c|c|c|c|c|c|}
\hline \multirow{2}{*}{$\begin{array}{l}\text { Experiment } \\
\text { Number }\end{array}$} & \multicolumn{3}{|c|}{ Parameter } & \multicolumn{3}{|c|}{ Experimental Result } \\
\hline & $\begin{array}{c}\text { Flow } \\
\text { Velocity } \\
\text { ( } \mathrm{ml} / \mathrm{min} \text { ) }\end{array}$ & $\begin{array}{c}\text { Jet } \\
\text { Distance } \\
\text { (cm) }\end{array}$ & $\begin{array}{c}\text { Hydrate } \\
\text { Saturation } \\
(\%)\end{array}$ & $\begin{array}{l}\text { Broken-rock } \\
\text { Volume }\left(\mathrm{cm}^{3}\right)\end{array}$ & $\begin{array}{l}\text { Pit Depth } \\
\text { (cm) }\end{array}$ & $\begin{array}{l}\text { Pit Diameter } \\
\text { (cm) }\end{array}$ \\
\hline 1 & 1100 & 0.5 & 50 & 81 & 7.9 & 5.07 \\
\hline 2 & 1300 & 0.5 & 50 & 104 & 8.52 & 5.3 \\
\hline 3 & 1500 & 0.5 & 50 & 137 & 8.86 & 5.82 \\
\hline 4 & 1700 & 0.5 & 50 & 187 & 9.02 & 6.82 \\
\hline
\end{tabular}

The pit crater and the shape of internal form was observed. For experiments 1, 2, and 3 , pit morphology had the same type, the diameter of the pit was obviously smaller than the bottom diameter, and the size of the pit was different. In experiment 4 , the bottom of the pit was the same as that of the first 3 groups, but the surface of the sample had a large area of breakage. In Experiment 1, the diameter of the pit was $2.71 \mathrm{~cm}$ and the maximum diameter of the bottom was $5.07 \mathrm{~cm}$. In Experiment 2, the diameter of the pit crater was $3.9 \mathrm{~cm}$ and the maximum diameter of the bottom was $5.3 \mathrm{~cm}$. In Experiment 3, the length of the pit crater was $4.36 \mathrm{~cm}$, the width of the pit crater was $3.32 \mathrm{~cm}$, and the maximum diameter of the bottom was $5.82 \mathrm{~cm}$. In Experiment 4, the diameter of the pit crater was $7.85 \mathrm{~cm}$ and the maximum diameter of the bottom was $6.82 \mathrm{~cm}$. Experimental breaking pits are shown in Figures 3-5.

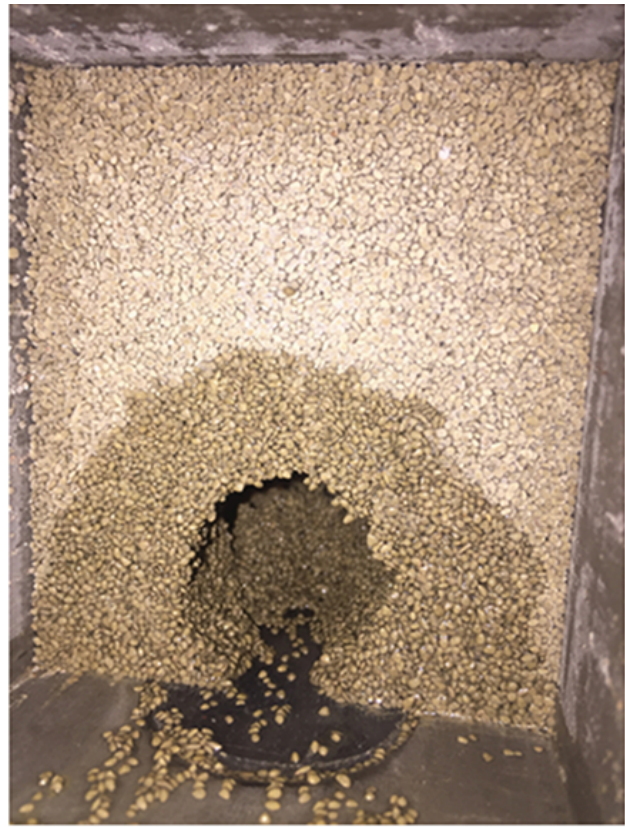

Pit crater

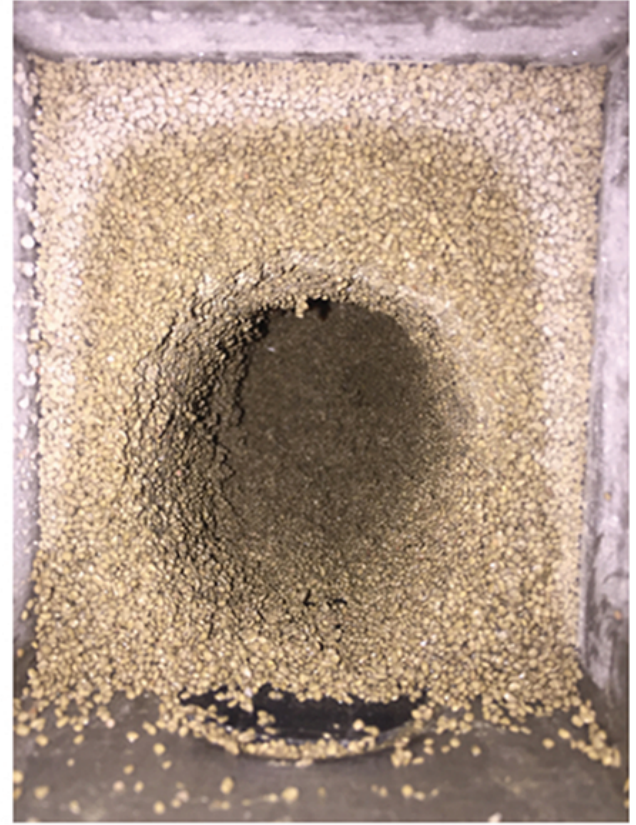

Internal of pit

Figure 3: Experiment 1 (1100 $\mathrm{ml} / \mathrm{min})$ breaking pit. 


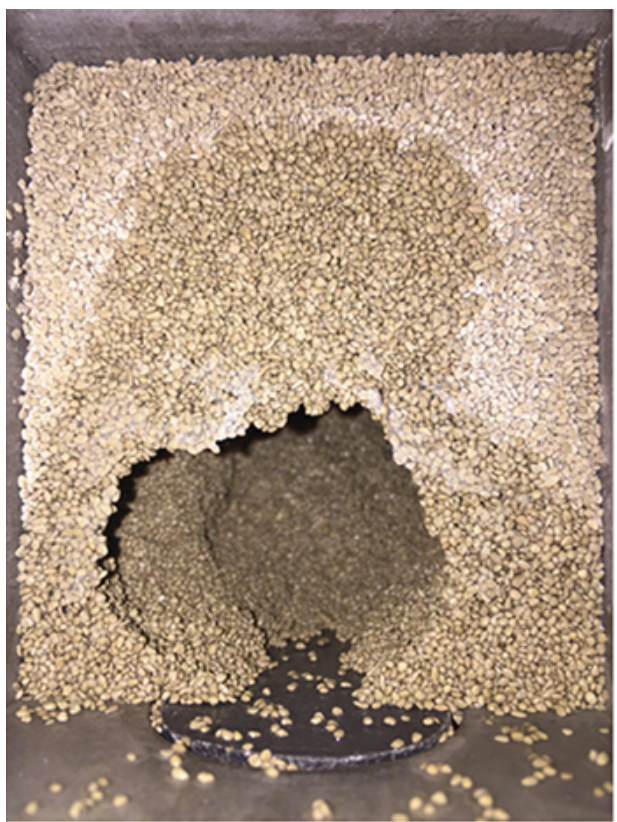

Pit crater

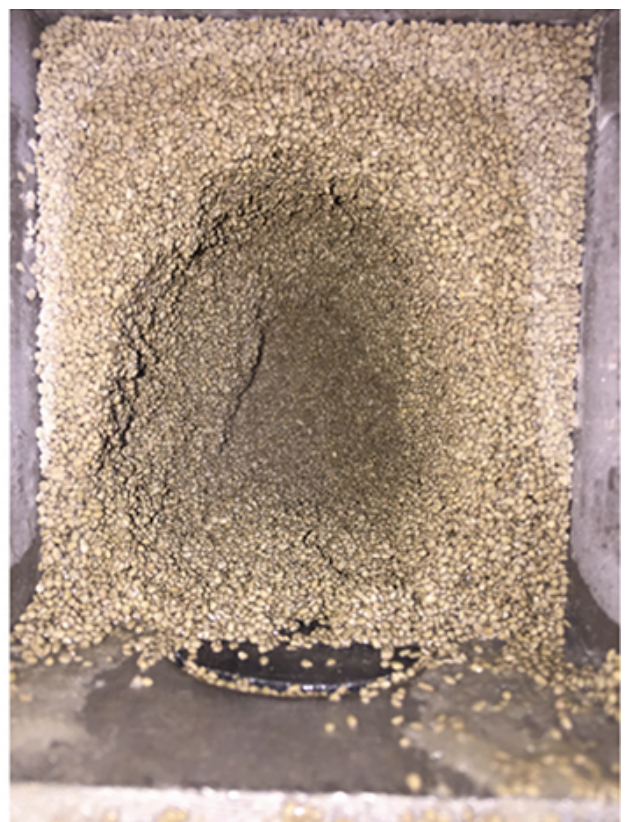

Internal of pit

Figure 4: Experiment 2 (1300 $\mathrm{ml} / \mathrm{min})$ breaking pit.

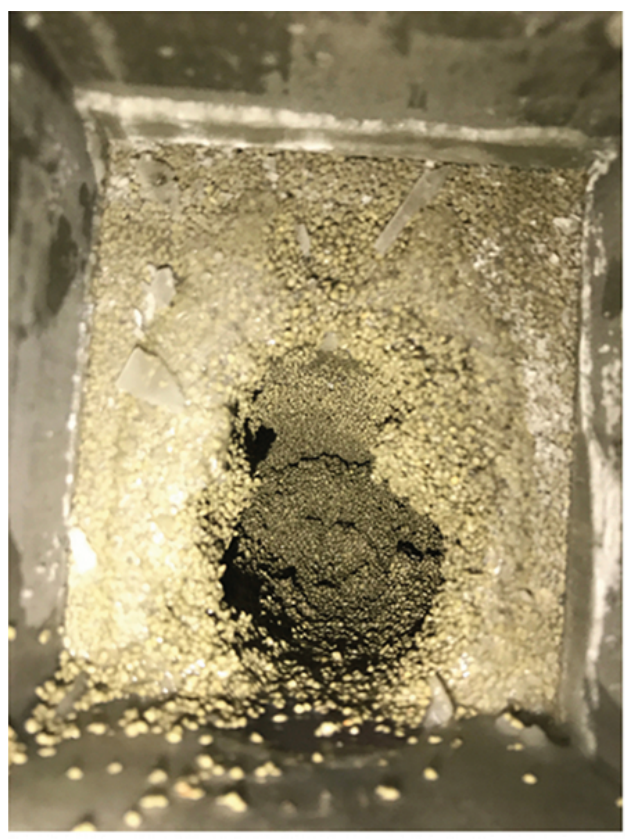

$1500 \mathrm{ml} / \mathrm{min}$

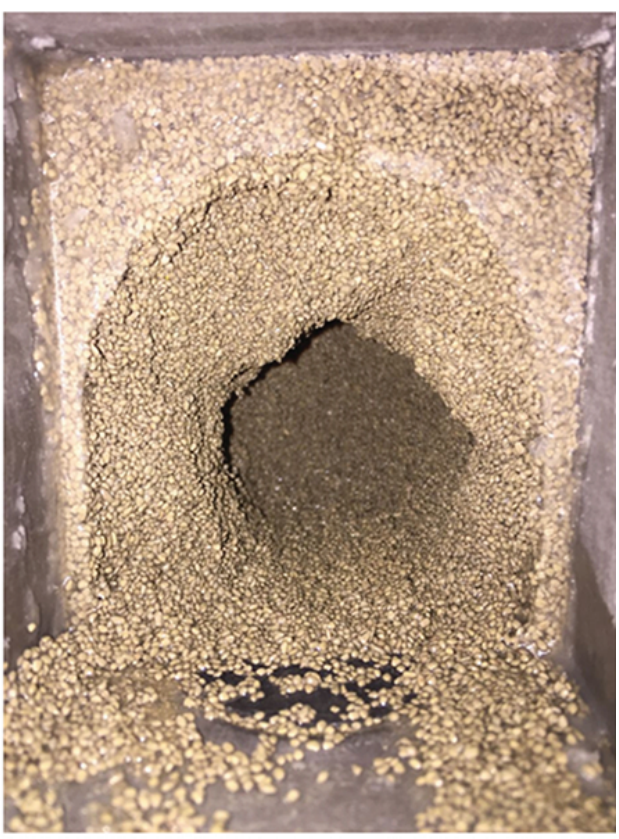

$1700 \mathrm{ml} / \mathrm{min}$

Figure 5: Experiment $3(1500 \mathrm{ml} / \mathrm{min})$ and experiment 4 (1700 $\mathrm{ml} / \mathrm{min})$ breaking pit. 


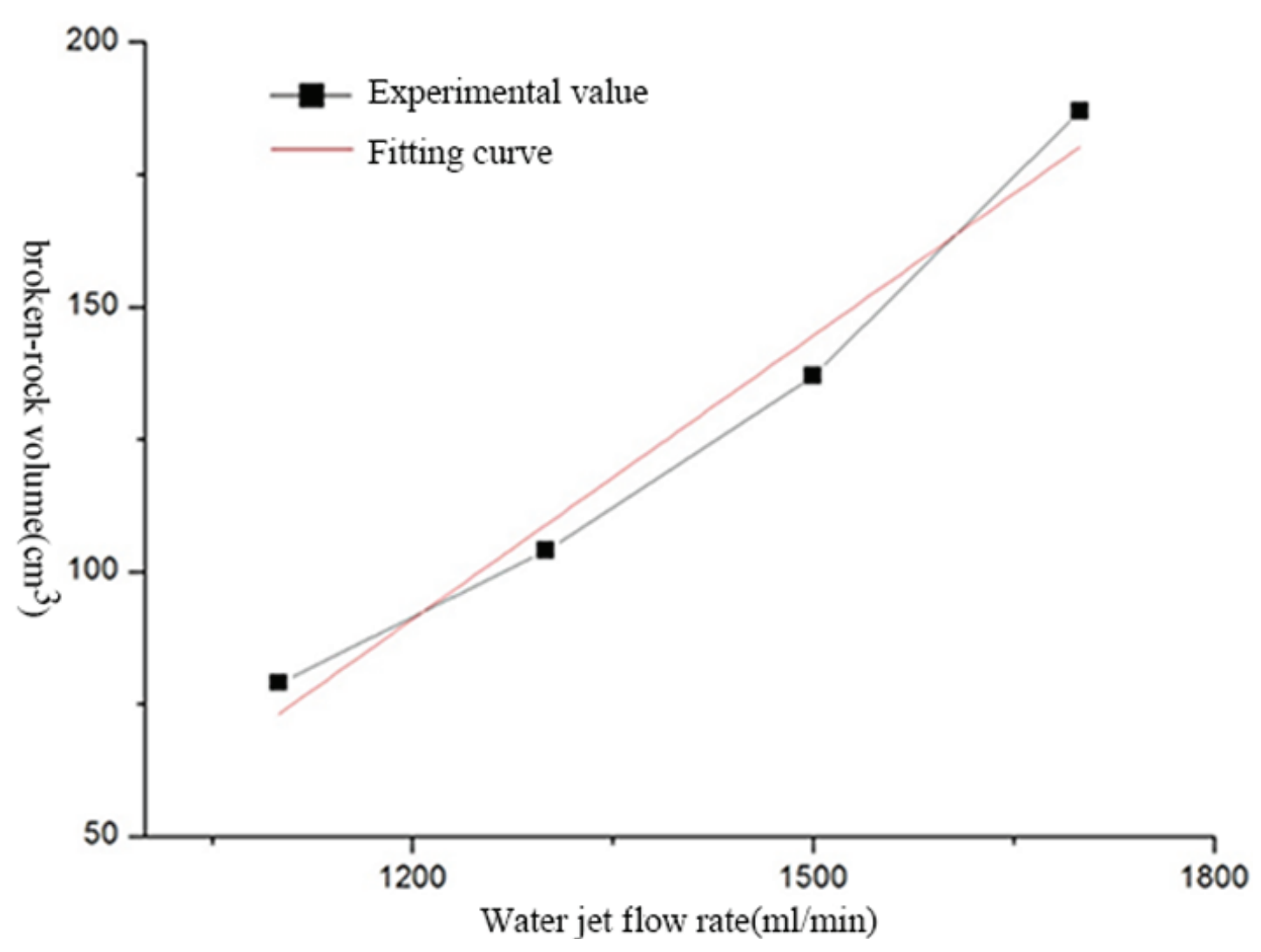

Figure 6: Jet flow and broken-rock volume diagram.

By analyzing the flow and broken-rock volume of water jet in the experimental of Table 2 , it was found that the water jet flow ( $x$-axis) had a linear relationship with the broken-rock volume ( $Y$-axis). The fitted equation is:

$$
V=0.1585 Q-128.15
$$

Jet flow and broken-rock volume diagram is shown in Figure 6 . When $\mathrm{V}=0$, the water jet flow (Q) was the critical velocity of hydrate bearing sediments under the action of water jet. Therefore, the critical breaking flow Qc $=808.5 \mathrm{ml} / \mathrm{min}$. The diameter of the nozzle $\mathrm{d}=1 \mathrm{~mm}$, and the critical breaking velocity of hydrate bearing sediments $\mathrm{V}_{C}=$ $16.84 \mathrm{~m} / \mathrm{s}$.

\section{Conclusion}

Characteristics and critical velocity of high pressure water jet breaking hydrate bearing sediments were studied. The three-dimensional size of the pit indicates that as the flow rate of the water jet increases, the broken-rock volume, the pit depth, and the internal diameter of the pit become larger. However, the growth rate of broken-rock 
volume increased and the growth rate of breaking depth decreased. The reason for this phenomenon is that when the flow rate of the water jet increases, the radial flow velocity generated by the water jet diffusion effect increases, strengthening the scouring effect of the pit surface sediments and enhancing the radial direction of the pit. The expansion causes the diameter of the lower part of the pit to become larger, resulting in the growth rate of broken-rock volume increase. On the other hand, as the breaking proceeds, the submerged fluid resistance and the reverse flow fluid flow rate increase together, resulting in an increase of the water jet resistance, and decrease of the energy for the downward crushing, so that the growth rate of the pit depth becomes small.

The pit crater and internal shape were analyzed. This is because when the water jet flow rate is increased, the scouring effect is stronger, and the flow velocity of return fluid is bigger, which causes greater tensile stress on the contact surface, resulting in a bigger surface cracking.

The critical breaking velocity of $M N G H$ bearing sediments $V_{C}=16.84 \mathrm{~m} / \mathrm{s}$, according to the results of laboratory experiments, high pressure and low temperature water jet method is feasible for hydrate exploitation.

As a new MNGH solid exploitation method, there are still many questions waiting to be carried out of the transition from laboratory experiments to practical projects. In the future, simulation experiments can be further improved; it is necessary to design a complete set of mining processes, conduct economic analysis, and, finally, carry out field experiments with a certain period of time.

\section{Funding}

This research was funded by the National Natural Science Foundation of China through the 'The research on rock fragmentation process and mechanism of marine gas hydrate bearing sediment under the action of high pressure and low temperature water jet' surface project [41672361, 2017/1-2020/12]. Also funded by the Science and Technology Development Plan Project of jilin province through the 'Research on Key Technologies of Marine Gas Hydrate Replacement exploitation' [20170414044GH, 2017/1-2019/12]. It was also supported by project the 'Oil shale underground in-situ development and utilization demonstration project' [SXGJSF2017-5, 2017/1-2022/12]. 


\section{References}

[1] Schoderbek, D., Farrell, H., and Howard, J. (2013). ConocoPhillips Gas Hydrate Production Test. NETL and US DOE.

[2] Yousif, M. H., Abass, H. H., Selim, M. S., et al. (1991). Experimental and theoretical investigation of methane-gas-hydrate dissociation in porous media. SPE Reservoir Engineering, vol. 6, no. 1, pp. 69-76.

[3] Chong, Z. R., Yang, S. H. B., Babu, P., et al. (2016). Review of natural gas hydrates as an energy resource: Prospects and challenges. Applied Energy, vol. 162, pp. 16331652.

[4] Max, M. D. and Johnson, A. H. (2016). Exploration and Production of Oceanic Natural Gas Hydrate. Berlin: Springer International Publishing.

[5] Tang, L. G., Li, X. S., Feng, Z. P., et al. (2007). Control mechanisms for gas hydrate production by depressurization in different scale hydrate reservoirs. Energy \& Fuels, vol. 21, no. 1, pp. 227-233.

[6] Fan, S., Zhang, Y., Tian, G., et al. (2006). Natural gas hydrate dissociation by presence of ethylene glycol. Energy \& Fuels, vol. 20, no. 1, pp. 419-425.

[7] Falser, S., Uchida, S., Palmer, A. C., et al. (2012). Increased gas production from hydrates by combining depressurization with heating of the wellbore. Energy Fuels, vol. 26, no. 10, pp. 6259-6267.

[8] Ruppel, C., Dickens, G. R., Castellini, D. G., et al. (2005). Heat and salt inhibition of gas hydrate formation in the northern Gulf of Mexico. Geophysical Research Letters, vol. 32, no. 4, pp. 353-368.

[9] Ohgaki, K., Takano, K., Sangawa, H., et al. (1996). Methane exploitation by carbon dioxide from gas hydrates - phase equilibria for $\mathrm{CO}_{2}-\mathrm{CH}_{4}$ mixed hydrate system. Journal of Chemical Engineering of Japan, vol. 29, no. 3, pp. 478-483.

[10] Demirbas, A. (2010). Methane Gas Hydrate. Berlin: Springer.

[11] Li, X. S., Xu, C. G., Zhang, Y., et al. (2016). Investigation into gas production from natural gas hydrate: A review. Applied Energy, vol. 172, pp. 286-322.

[12] Suzuki, S. and Kuwano, R. (2016). Evaluation on stability of sand control in mining methane hydrate. Production Research, vol. 68, no. 4, pp. 311-314.

[13] Murphy, A., Soga, K., and Yamamoto, K. (2017). A laboratory investigation of sand production simulating the 2013 Daini- Atsumi Knoll gas hydrate production trial using a high pressure plane strain testing apparatus. Proceedings of the 9th International Conferences on Gas Hydrate. Denver, Colorado, USA: ICGH9. 
[14] Konno, Y., Oyama, H., Nagao, J., et al. (2010). Numerical analysis of the dissociation experiment of naturally occurring gas hydrate in sediment cores obtained at the eastern Nankai Trough, Japan. Energy Fuels, vol. 24, no. 12, pp. 6353-6358.

[15] Kono, H. O., Narasimhan, S., Song, F., et al. (2002). Synthesis of methane gas hydrate in porous sediments and its dissociation by depressurizing. Powder Technology, vol. 122, no. 2, pp. 239-246.

[16] Castaldi, M. J., Zhou, Y., and Yegulalp, T. M. (2007). Down-hole combustion method for gas production from methane hydrates. Journal of Petroleum Science \& Engineering, vol. 56, no. 1, pp. 176-185.

[17] Yezdimer, E. M., Cummings, P. T., and Chialvo A. A. (2002). Determination of the Gibbs free energy of gas replacement in SI Clathrate hydrates by molecular simulation. Journal of Physical Chemistry A, vol. 106, no. 34, pp. 7982-7987.

[18] Dallimore, S. R. and Collett, T. S. (2005). Scientific results from the Mallik 2002 gas hydrate production research well program, Mackenzie Delta, Northwest Territories, Canada. Bulletin of the Geological Survey of Canada, p. 585.

[19] Collett, T. S., Lewis, R. E., Winters, W. J., et al. (2011). Downhole well log and core montages from the Mount Elbert Gas Hydrate Stratigraphic Test Well, Alaska North Slope. Marine \& Petroleum Geology, vol. 28, no. 2, pp. 561-577.

[20] Cyranoski, D. (2013). Japanese test coaxes fire from ice. Nature, vol. 496, no. 7446, p. 409.

[21] Zhang, X. H., Xiao-Bing, L. U., and Liu, L. L. (2014). Advances in natural gas hydrate recovery methods. Progress in Geophysics, vol. 29, pp. 858-869.

[22] Dong, H., Wu, K., and Wu, B. (2017). Modular production system with decomposing natural gas hydrate and separating the sediments from NGH slurry on seabed. Proceedings of the 9th International Conference on Gas Hydrates. Denver, Colorado, USA.

[23] Kaisong, W., Tongwei, J., Dong, L., et al. (2017). Research on design of mining tools of marine gas hydrates reservoirs. Mechanical Science and Technology for Aerospace Engineering, vol. 36, no. 2, pp. 225-231.

[24] Zhou, S. W., Chen, W., Li, Q. P., et al. (2017). Research and development of solidstate fluidized test mining technology for deep-water shallow non-diagenetic gas hydrate. China Offshore Oil and Gas, vol. 29, no. 04, pp. 1-8. 